\title{
Command or Obey? Homologous Neurons Differ in Hierarchical Position for the Generation of Homologous Behaviors
}

\author{
(ㄱ)Akira Sakurai ${ }^{1}$ and $\odot$ Paul S. Katz ${ }^{2}$ \\ ${ }^{1}$ Neuroscience Institute, Georgia State University, Atlanta, Georgia 30302, and 2Department of Biology, University of Massachusetts, Amherst, \\ Massachusetts 01003
}

In motor systems, higher-order neurons provide commands to lower-level central pattern generators (CPGs) that autonomously produce rhythmic motor patterns. Such hierarchical organization is often thought to be inherent in the anatomical position of the neurons. Here, however, we report that a neuron that is member of a CPG in one species acts as a higher-order neuron in another species. In the nudibranch mollusc, Melibe leonina, swim interneuron 1 (Sil) is in the CPG underlying swimming, firing rhythmic bursts of action potentials as part of the swim motor pattern. We found that its homolog in another nudibranch, Dendronotus iris, serves as a neuromodulatory command neuron for the CPG of a homologous swimming behavior. In Dendronotus, Sil fired irregularly throughout the swim motor pattern. The burst and spike frequencies of Dendronotus swim CPG neurons correlated with Sil firing frequency. Sil activity was both necessary and sufficient for the initiation and maintenance of the swim motor pattern. Each Sil was electrically coupled to all of the CPG neurons and made monosynaptic excitatory synapses with both Si3s. Sil also bilaterally potentiated the excitatory synapse from Si3 to Si2. "Virtual neuromodulation" of both Si3-to-Si2 synapses using dynamic clamp combined with depolarization of both Si3s mimicked the effects of Sil stimulation on the swim motor pattern. Thus, in Dendronotus, Sil is a command neuron that turns on, maintains, and accelerates the motor pattern through synaptic and neuromodulatory actions, thereby differing from its homolog in Melibe in its functional position in the motor hierarchy.

Key words: central pattern generator; command neuron; dynamic clamp; evolution; half-center oscillator; neuromodulation

\section{Significance Statement}

Cross-species comparisons of motor system organization can provide fundamental insights into their function and origin. Central pattern generators (CPGs) are lower in the functional hierarchy than the neurons that initiate and modulate their activity. This functional hierarchy is often reflected in neuroanatomical organization. This paper definitively shows that an identified cerebral ganglion neuron that is a member of a CPG underlying swimming in one nudibranch species serves as a command neuron for the same behavior in another species. We describe and test the synaptic and neuromodulatory mechanisms by which the command neuron initiates and accelerates rhythmic motor patterns. Thus, the functional position of neurons in a motor hierarchy can shift from one level to another over evolutionary time.

\section{Introduction}

A hierarchical organization implies directionality, with higherlevel components issuing commands that are carried out by lower

\footnotetext{
Received Dec. 22, 2018; revised April 20, 2019; accepted May 8, 2019.

Author contributions: A.S. and P.S.K. designed research; A.S. performed research; A.S. analyzed data; A.S. and P.S.K. wrote the paper.

This work was supported by NSF Grant IOS-1455527 to P.S.K. We thank Dr. Andrey Shilnikov for helpful discussions, and Trevor Fay and Andrew Kim at the Monterey Abalone Company for their efforts in collecting and shipping animals to meet our needs.

The authors declare no competing financial interests.

Correspondence should be addressed to Akira Sakurai at akira@gsu.edu.
}

levels (Kupfermann and Weiss, 1978). This organization is often considered to be inherent in the neuroanatomy of motor systems. For example, brainstem neurons provide commands to locomotor central pattern generators (CPGs) in the spinal cord (Dubuc et al., 2008; Roberts et al., 2008; Kiehn, 2016). Similarly, in invertebrates, commands for locomotion and feeding come from neurons outside of the CPG and often in other ganglia (Gillette et al., 1982; Gamkrelidze et al., 1995; Panchin et al., 1995; Frost and Katz, 1996; Stein, 2009; Puhl et al., 2012). Here, we show that the 
hierarchical position of a neuron differs in two species even though the neuron is involved in the production of the same behavior in those species.

The nudibranch molluscs, Melibe leonina and Dendronotus iris exhibit characteristic swimming behaviors that consist of a series of laterally-directed body flexions in which the whole body alternately bends toward the left and right sides (Sakurai et al., 2011). A phylogenetic analysis indicates that the most recent common ancestor of these species likely swam in this manner, making the swimming behaviors homologous (Goodheart et al., 2015; Sakurai and Katz, 2017).

In addition to the behavioral homology, a bilaterally represented neuron was shown to be homologous. First identified in Melibe, the neuron was named Swim interneuron 1 (Si1) because of its involvement in swim CPG (Thompson and Watson, 2005). It was previously established that $\mathrm{Sil}$ in Dendronotus is homologous to Sil in Melibe based on its conserved neuronal anatomy (soma location in the cerebral ganglion, proximity to a cluster of serotonergic neurons, unique axon shape; Fig. $1 A 1, B 1$ ), and neurochemistry (FMRFamide immunoreactivity), which uniquely identify this neuron in several nudibranch species (Sakurai et al., 2011; Newcomb et al., 2012; Gunaratne et al., 2017). Homologous neurons are a classic feature of gastropod nervous systems (Croll, 1987; Bulloch and Ridgway, 1995; Katz and Quinlan, 2019).

In Melibe, Si1 is electrically-coupled to the ipsilateral Si2 and the contralateral Si4 in the pedal ganglia (Fig. 1A2; Sakurai et al., 2014). Each neuron inhibits its contralateral counterpart to form the main half-center oscillator. The burst period of the main half-center oscillator is regulated by inhibitory synapses from $\mathrm{Si} 3$ (Fig. 1A2; Sakurai et al., 2014). Sil also synapses onto Si3 on both sides, which plays roles in setting the phase relationship and promoting the transition of Si3 bursting from one side to the other (Sakurai et al., 2014). As it is part of the CPG, tonic depolarization or hyperpolarization of one Sil interferes with rhythmic activity (Figs. 1A3, 4; Sakurai et al., 2011).

In contrast to Melibe, in Dendronotus, Si1 has no reciprocal inhibition and is not a member of the CPG (Fig. 1B2); each Sil is electrically coupled to both left and right Si2 and fires irregularly throughout the swim motor pattern (Sakurai et al., 2011; Sakurai and Katz, 2016, 2017). The swim CPG is composed of Si2 and Si3, which form the half-center oscillator through reciprocal inhibition of their contralateral counterparts (Fig. 1B2). A homolog of $\mathrm{Si} 4$ has not been identified. It was shown that tonic depolarization of one Sil speeds up bursting, whereas hyperpolarization of Sil slows it down (Figs. 1B3,4; Sakurai et al., 2011). However, the mechanism of such modulatory action and its roles in the motor pattern generation were not previously elucidated.

Here, we find that unlike its homolog in Melibe, Sil in Dendronotus is a command neuron for swimming; its spiking activity is necessary for the production of the motor pattern and sufficient to elicit it. Depolarizing Sil initiates, maintains, and accelerates the swim motor pattern through its synaptic and neuromodulatory actions on the members of the swim CPG. Thus, homologous neurons occupy different positions in the motor hierarchies of Dendronotus and Melibe.

\section{Materials and Methods}

Animals. Adult specimens of Melibe leonina and Dendronotus iris were collected on the west coast of North America by Monterey Abalone Company, Marinus Scientific, and Living Elements. Animals were shipped to Atlanta overnight and kept in artificial seawater (Instant Ocean) at $10-$ $12^{\circ} \mathrm{C}$ with a $12 \mathrm{~h}$ light/dark cycle. Elemental composition of the Instant
Ocean is as follows ( in mM): $444 \mathrm{Na}, 9.5 \mathrm{~K}, 9.2 \mathrm{Ca}, 49.4 \mathrm{Mg}, 519 \mathrm{Cl}, 26$ $\mathrm{SO}_{4}, 2.3 \mathrm{HCO}_{3}, 0.4 \mathrm{H}_{3} \mathrm{BO}_{3}, 0.3 \mathrm{Br}$ (Creswell, 1993).

Brain preparation. The animal was first anesthetized by injecting $0.33 \mathrm{M}$ $\mathrm{MgCl}_{2}$ solution into the body cavity. Then, the left body wall near the esophagus was cut open and the brain, consisting of the left and right pedal and fused cerebral-pleural ganglia, was removed, together with a portion of the esophagus. The tissue was placed in a Petri dish lined with Sylgard 184 (Dow Corning) and filled with artificial seawater kept at $4^{\circ} \mathrm{C}$. The composition of the artificial sea water was as follows (in $\mathrm{mM}$ ): 420 $\mathrm{NaCl}, 10 \mathrm{KCl}, 10 \mathrm{CaCl}_{2}, 50 \mathrm{MgCl}_{2}, 11 \mathrm{D}$-glucose, and 10 HEPES, $\mathrm{pH}$ 7.6. Connective tissue and brain sheath were manually dissected from the dorsal side of the cerebral ganglia and pedal ganglia with forceps and scissors. After desheathing, all nerve roots except for pedal nerve 3 (PdN3) were crushed with forceps to avoid spontaneous movement of any muscle tissue attached to the brain. The desheathed brain was then continuously superfused with artificial seawater at a rate of $0.5-1.0 \mathrm{ml} /$ $\min$ at $10^{\circ} \mathrm{C}$ and allowed to rest for $>1 \mathrm{~h}$ before starting electrophysiological experiments.

In some experiments, spontaneous neuronal activity was suppressed by applying high divalent cation (Hi-Di) saline, which raises the threshold for neuronal spiking. The composition of the Hi-Di saline was as follows (in mM): $285 \mathrm{NaCl}, 10 \mathrm{KCl}, 25 \mathrm{CaCl}_{2}, 125 \mathrm{MgCl}_{2}, 11$ D-glucose, and 10 HEPES, pH 7.6. Hi-Di saline was used to examine direct monosynaptic and electrical connections between neurons. For zero calcium experiments, $\mathrm{CaCl}_{2}$ was replaced by $\mathrm{MgCl}_{2}$ to block chemical synaptic transmission.

Electrophysiology. For intracellular recording of neuronal membrane potential, sharp microelectrodes were made from borosilicate glass capillaries (outer diameter, $1.0 \mathrm{~mm}$; inner diameter, $0.78 \mathrm{~mm}$ ) with a micropipette puller (Model P-97, Sutter Instrument). The electrodes were filled with $2 \mathrm{~m}$ potassium acetate and $0.1 \mathrm{~m}$ potassium chloride. The resistance of the microelectrodes was within the range from 20 to $60 \mathrm{M} \Omega$. The membrane potential recordings of the swim interneurons were made using AxoClamp 2B amplifier (Molecular Devices). The output bandwidth of the amplifier was set to $3 \mathrm{kHz}$. All the output signals from these amplifiers were digitized at a sampling frequency of $>2 \mathrm{kHz}$ using a Micro1401 A/D converter (Cambridge Electronic Design) and acquired on a desktop computer running Windows 10 with Spike2 software v8 (Cambridge Electric Design).

Neurons were stimulated by injecting current steps (0.5-3 nA) through a bridge-balanced electrode. To measure electrical connections between two neurons, one of them was impaled with two microelectrodes, one for membrane potential recording and the other for current injection and negative current pulses of varying amplitude $(-1$ to -4 $\mathrm{nA}$ ) was injected through the second electrode. The current/voltage relationship was always linear in the neuron being injected with the current pulses of varying amplitude when the voltage change was measured at the peak. To evoke the swim motor pattern, either left or right PdN3 was stimulated with a train of voltage pulses $(5 \mathrm{~V}, 1 \mathrm{~ms})$ at $5 \mathrm{~Hz}$ for $1-3 \mathrm{~s}$ applied through a suction pipette made from polyethylene tube. A train of stimulus pulses were generated by MASTER- 8 pulse stimulator (AMPI) and fed to the electrode through a stimulus isolator (ISO-Flex, AMPI).

Dynamic clamp. To experimentally boost the strength of the Si3-to-Si2 synapse, we created artificial synaptic currents simultaneously by running Dynamic Clamp software StdpC (Kemenes et al., 2011) on a second Windows computer. Each Si2 was impaled with two microelectrodes, one for membrane potential recording and the other for current injection. Each Si3 was impaled with one microelectrode and the amplifier was set to the discontinuous current-clamp mode. The artificial synaptic current, $I_{\mathrm{Syn}}$, was calculated as described previously (Destexhe et al., 1994; Sharp et al., 1996; Kemenes et al., 2011):

$$
I_{\text {Syn }}=g_{\text {Syn }} S(t)\left[V_{\text {Syn }}-V_{\text {post }}(t)\right]
$$

where $S(t)$ is the instantaneous synaptic activation, $g_{\mathrm{Syn}}$ is the maximum synaptic conductance, and $V_{\mathrm{Syn}}$ is the reversal potential of the synapse. In this study $V_{\text {Syn }}$ was set to $0 \mathrm{mV}$ for the Si3-to-Si2 synapses based on previous measurements under voltage-clamp (Sakurai and Katz, 2017). 


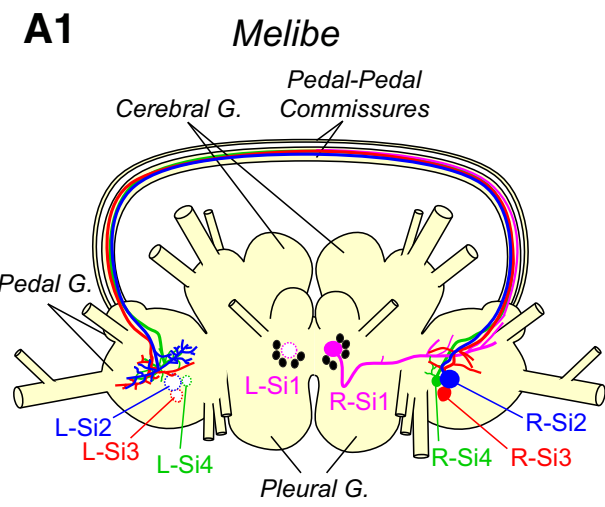

A2

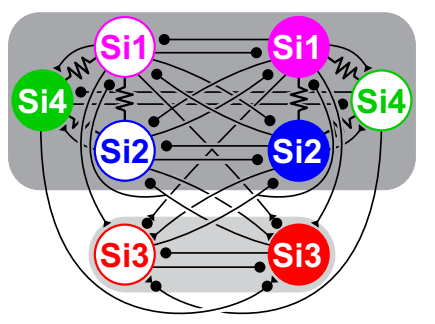

A3

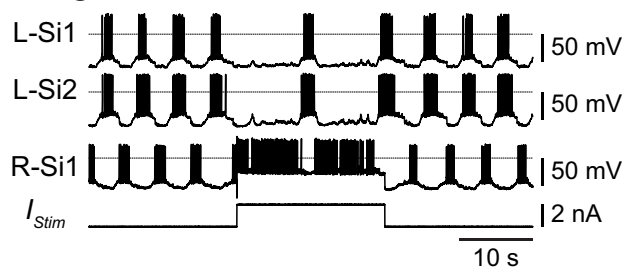

A4

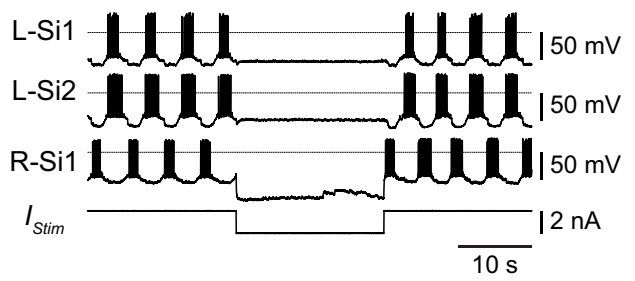

B1 Dendronotus

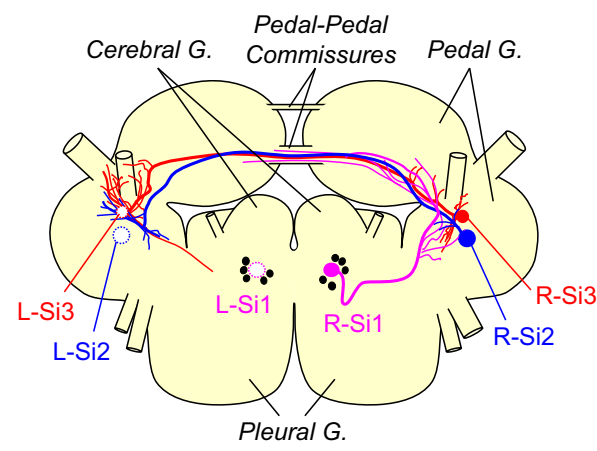

B2

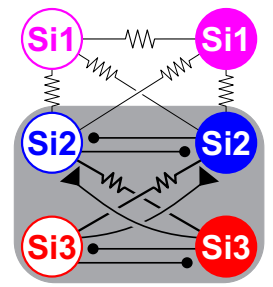

B3

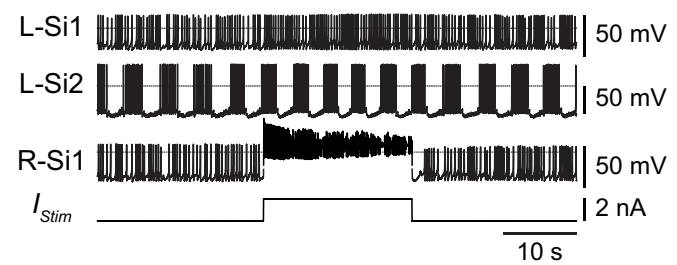

B4

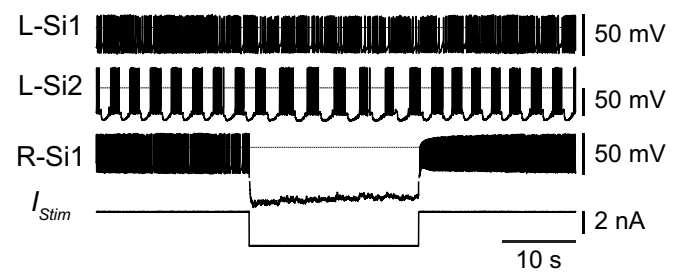

Figure 1. The swim CPGs in Melibe and Dendronotus and their characteristics. $A$, A schematic diagram of the Melibe brain showing the locations of swim CPG neurons (A1), the swim CPG (A2), and intracellular recordings of both left and right Si1s and left Si2 exhibiting the swim motor pattern $(\boldsymbol{A} \mathbf{3}, \boldsymbol{A 4})$. $\boldsymbol{A}$, The Si1 soma is located in the cerebral ganglion $(\mathrm{G})$ and has an axon with a bend that projects to the ipsilateral pedal ganglion before continuing through the pedal-pedal commissure to the contralateral pedal ganglion. The other swim CPG neurons are located in the pedal ganglion and project contralaterally through the pedal-pedal commissure. Black dots represent previously identified serotonin-immunoreactive neurons (Newcomb et al., 2006). A2, The Melibe swim CPG consists of mutually inhibitory main half-center oscillator (Si1, Si2, Si4, darker rounded rectangle), which is regulated by Si3 (lighter rounded rectangle). Filled circles indicate neurons with somata on the right side of the brain, open circles on the left. Lines terminating in circles indicate inhibitory synapses; those with triangles are the excitatory synapses. Resistor symbols indicate electrical connections. Each neuron forms reciprocal inhibitory synapses with its contralateral counterpart. Based on Sakurai et al. (2014). A3, Depolarization of Si1 by current injection ( $2 \mathrm{nA}$ ) interrupted the swim motor pattern. $\boldsymbol{A 4}$, Hyperpolarization of Si1 by injection of negative current $(-2 \mathrm{nA})$ halted the motor pattern. $\boldsymbol{B}$, The locations of neurons in the Dendronotus brain $(\boldsymbol{B} 1)$, organization of the swim CPG (B2), and intracellular recordings of both left and right Si1s and left Si2 (B3, B4).B1, Although the overall shape of the brain differs from Melibe, homologous neurons are located in similar positions and have similar axon projections. B2, Two bilateral pairs of neurons (Si2 and Si3) constitute the half-center oscillator, forming reciprocal inhibition with their contralateral counterparts. Si3 makes a strong excitatory synapse and electrical connection onto the contralateral Si2. B3, Depolarization of Si1 by current injection (2 nA) accelerated the bursting rhythm of Si2. B4, Hyperpolarization of Sil by current injection $(-3 \mathrm{nA})$ slowed down the rhythm.

The instantaneous activation, $S(t)$ is given by the differential equation:

$$
\left(1-S_{\infty}\left(V_{\mathrm{Pre}}\right)\right) \tau_{\mathrm{Syn}} \frac{d S}{d t}=\left(S_{\infty}\left(V_{\mathrm{Pre}}\right)-S(t)\right)
$$

where

$$
S_{\infty}\left(V_{\text {Pre }}\right)=\left\{\begin{array}{ll}
\tanh \left[\frac{V_{\text {Pre }}-V_{\text {Thresh }}}{V_{\text {Slope }}}\right] & \text { if } V_{\text {Pre }}>V_{\text {Thresh }} . \\
0 & \text { otherwise }
\end{array} .\right.
$$

$S_{\infty}$ is the steady-state synaptic activation and $\tau_{\text {Syn }}$ is the time constant for synaptic decay. $V_{\mathrm{Pre}}$ is the presynaptic membrane potential of $\mathrm{Si} 3$ and
$V_{\text {Thresh }}$ is the threshold potential for the release of neurotransmitter, which was set to be $50 \%$ of the amplitude of the smallest Si3 action potentials. $V_{\text {Slope }}$ is the synaptic slope parameter of the activation curve. In this study, $\tau_{\text {Syn }}$ and $V_{\text {Slope }}$ was set to $40 \mathrm{~ms}$ and $25 \mathrm{mV}$, respectively, as described previously (Sakurai and Katz, 2016, 2017). $g_{\text {Syn }}$ was varied between 40 and $160 \mathrm{nS}$.

Experimental design and statistical analysis. A train of Si2 spikes was counted as a burst if the spike interval was $<0.5 \mathrm{~s}$ and the duration of the spike train was $>0.5 \mathrm{~s}$. The burst frequency was measured by the interval between the median spike in each burst of Sil or Si2 and averaged over $30 \mathrm{~s}$. When bursting in left-right alternation was not detected as de- 
A
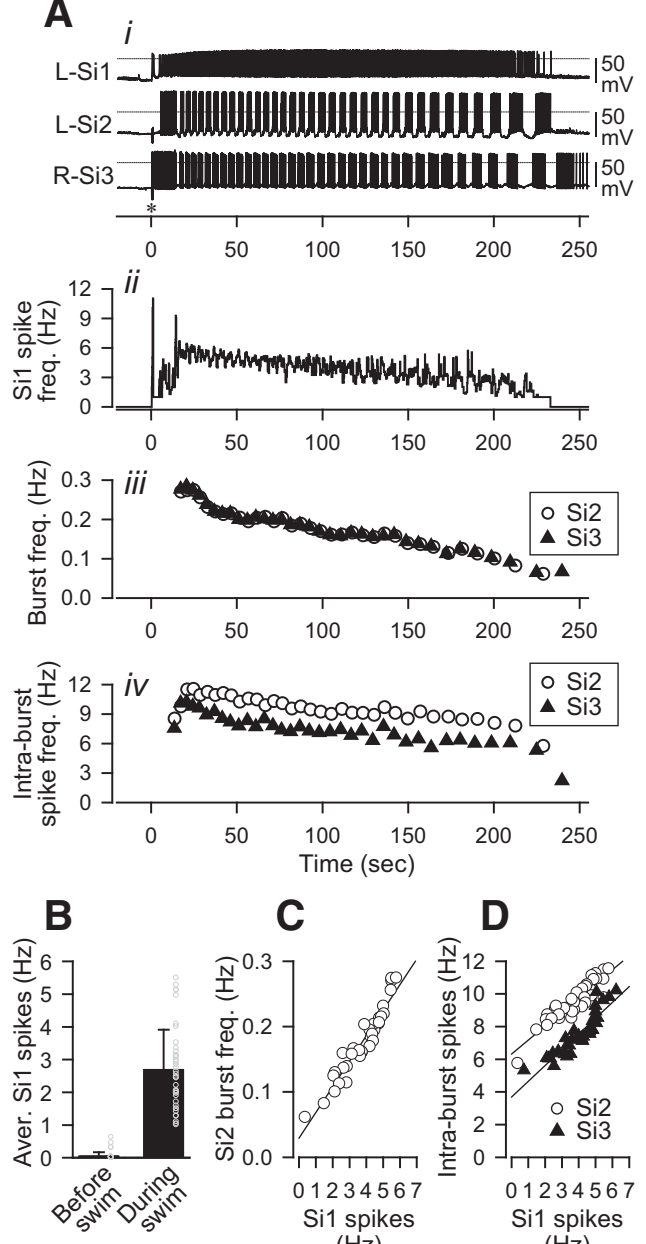

$(\mathrm{Hz})$

$(\mathrm{Hz})$

Figure 2. Si1 spiking correlates with the Dendronotus swim motor pattern. $A$, Stimulation of a body wall nerve (PdN3) with a train of voltage pulses $(10 \mathrm{~V}, 1.0 \mathrm{~ms}, 5 \mathrm{~Hz}$ for $0.8 \mathrm{~s}$ at asterisk) evoked the swim motor pattern as recorded simultaneously in the left Si1, left Si2 and right Si3 (Ai). Si1 fired throughout the motor pattern, but did not burst, whereas Si2 and Si3 exhibited rhythmic bursts of action potentials. The dotted horizontal line on each trace indicates $0 \mathrm{mV}$. The graphs below the traces show running averages of spike rate ( $\mathrm{Hz}$ ) in Si1 (Aii), burst rate $(\mathrm{Hz})$ of L-Si2 (open circles), and R-Si3 (filled triangles; Aiii), and intraburst spike rate (Hz) for L-Si2 (open circles) and R-Si3 (filled triangles; Aiv) from the raw data in Ai. B, Bar graph of averaged spike frequency of Si1 before and during the swim motor pattern. There was a significant difference between the average spike frequency of Si1 before and during the swim motor pattern $(p<0.0001$ by paired $t$ test, $N=40$ ). The Si1 spike frequency was measured in the $30-40$ s time window before a swim episode (white) and after the onset of the swim motor pattern (black). C, The instantaneous frequency of Si2 bursts (34 bursts) showed a positive correlation with the Si1 spike rates $(\mathrm{Hz} ; p<0.0001$, Pearson correlation coefficient $(\mathrm{PCC})=$ 0.96 . The Si1 spike frequencies were measured at corresponding time windows. $\boldsymbol{D}$, The intraburst spike rates $(\mathrm{Hz})$ of 35 bursts in $\mathrm{Si} 2$ and $\mathrm{Si} 3$ both showed a positive correlation with the Si1 spike rates ( $\mathrm{Hz} ; \mathrm{Si}, \mathrm{p}<0.0001, \mathrm{PCC}=0.91)$. Data in $\boldsymbol{A}, \boldsymbol{C}$, and $\boldsymbol{D}$ were from the same preparation.

scribed previously (Sakurai and Katz, 2016), then the burst frequency was considered as $0 \mathrm{~Hz}$ and the average spike frequency in the duration of $>30 \mathrm{~s}$ was used as the intraburst spike frequency. Normalized EPSP/C amplitudes in the Figure $7 C$ and $D$ graph were calculated by dividing the amplitude of EPSP or EPSC by the averaged amplitude before the Si1 stimulation.

Statistical comparisons were performed using SigmaPlot v12.5 (Jandel Scientific) for Student's $t$ test (one-tailed), paired $t$ test [see Fig. 7Cii $(N=$ 4), Dii $(N=9)$ ], Pearson correlation [Fig. $2 C(N=34$ bursts $), D(N=35$ bursts)], and one-way repeated-measures ANOVA [see Figs. $5 B, C(N=$ 11 preparations), $8 D 1, D 2(N=8$ preparations $), 9 D(N=11$ preparations), $E(N=7$ preparations)] with Holm-Sidak pairwise multiple- comparison procedures. Shapiro-Wilk test was used to test normality of data structure. When the normality test failed, Wilcoxon signed rank test was used instead of a paired $t$ test [Figs. $2 B(N=40), 6 C(N=25)$ ]. Results are expressed as the mean in Figure $7 \mathrm{Ci}, \mathrm{Di}$, the mean $\pm \mathrm{SD}$ in Figures $2 B, 5 B, C, 8 D 1, D 2$, and $9 D, E$, or plotted in a box plot in Figure $6 C$. The experimental manipulations of varying strength were given with random order. Missing data were due to the loss of intracellular recording from the neurons.

\section{Results}

Sil firing frequency is correlated with the intensity of the motor pattern

Sil was previously shown to be extrinsic to swim CPG in Dendronotus (Sakurai et al., 2011). Although it is active throughout the motor program, Sil does not fire bursts of action potentials like the CPG neurons do (Fig. $2 A$ i). In $90 \%$ of preparations, Si1 was silent before the onset of the swim motor pattern $(N=36$ of 40). After triggering the motor pattern with electrical stimulation of a body wall nerve, Sil started firing action potentials or significantly increased its ongoing spike rate, which peaked quickly before gradually decreasing (Fig. 2Aii). There was a significant difference between the average spike frequency of Sil before and during the swim motor pattern $(N=40$ preparations; Fig. 2B).

In parallel with the increase in Sil spiking, the burst frequency and intraburst spike frequency of $\mathrm{Si} 2$ and $\mathrm{Si} 3$ also rapidly increased at the beginning of the swim motor bout and then slowly declined over the course of the bout (Fig. 2Aiii,Aiv). There was a significant correlation between the Si2 burst frequency and Si1 spike frequency (Fig. 2C). Significant positive correlations were seen in $88 \%$ of preparations ( 29 of 33 ) with the average Pearson correlation coefficient of $0.57 \pm 0.18$. Similarly, the intraburst spike frequencies of Si2 and Si3 also correlated with Sil spiking (Fig. 2D). Significant positive correlations were seen in all 33 preparations with the average Pearson correlation coefficient of $0.70 \pm 0.15$.

\section{Sil spiking is necessary and sufficient for initiation and maintenance of the swim motor pattern}

The swim motor pattern could be terminated by halting Sil activity. Hyperpolarizing current injection into both Sils caused a reduction in spiking in $\mathrm{Si} 2$ and $\mathrm{Si}$, leading to a cessation of bursting (Fig. 3A). When the Sils were released from hyperpolarization, the motor pattern resumed. Similar results were seen in all preparations examined $(N=14)$. In addition, in $40 \%$ of preparations, suppression of spiking in just one Sil terminated the motor pattern $(N=6$ of 15$)$. These results indicate that spiking of at least one Sil was necessary for the maintenance of the swim motor pattern.

In quiescent preparations, injecting superthreshold depolarizing current into one Sil $(N=38)$ or both Sils $(N=21)$ induced bursting in the swim CPG neurons (Fig. $3 B ; N=53$ total preparations). Bursting activity slowly dissipated after termination of the current pulse. Thus, although not a member of the CPG itself, Sil has a command neuron-like function: it is sufficient to initiate bursting and necessary to maintain it.

\section{Sil provides excitatory synaptic drive to $\mathrm{Si} 3$}

Previously established connectivity of Sil is summarized in Figure $1 B$. In this study we determine that Sil has additional synaptic connections (compare Fig. 10A). It was previously shown that each Sil is electrically coupled to both left and right Si2s (Sakurai et al., 2011). We found that Sil also has chemical and electrical 

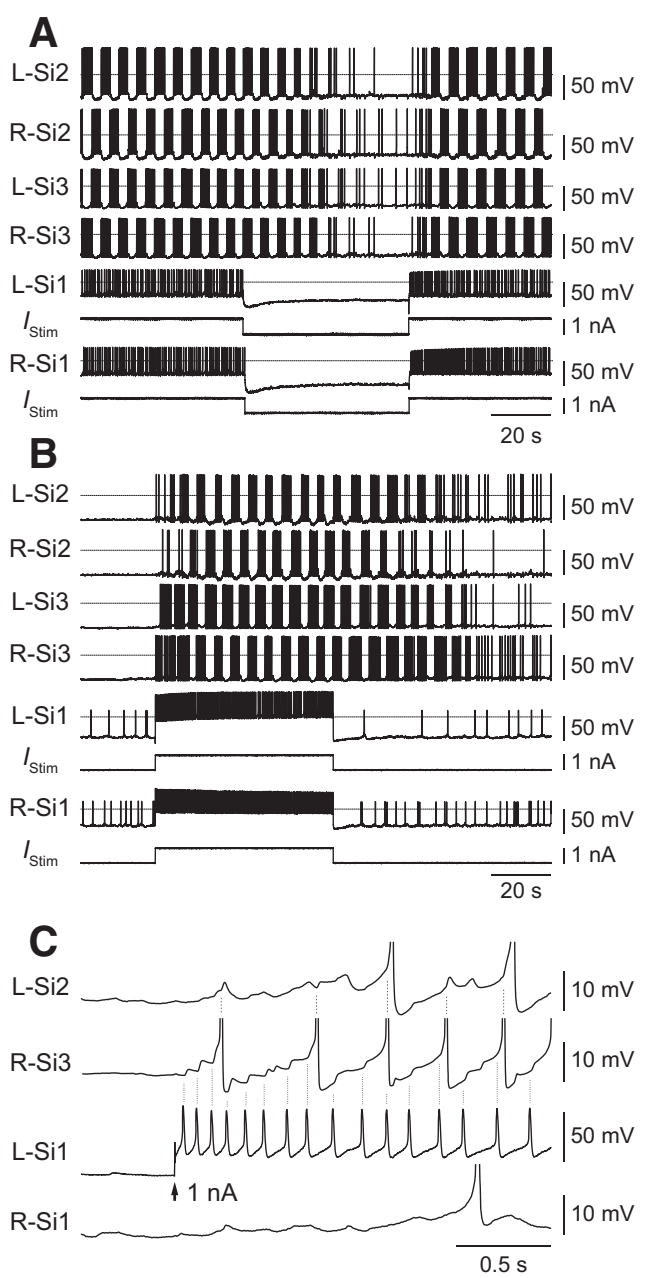

Figure 3. Si1 spiking is necessary and sufficient for initiation and maintenance of the Dendronotus swim motor pattern. $\boldsymbol{A}, \boldsymbol{B}$, The activity of six neurons were recorded simultaneously. $\boldsymbol{A}$, Hyperpolarization of both Si1s $(-1 \mathrm{nA})$ slowly halted an ongoing swim motor pattern recorded in both Sizs and Si3s. The swim motor pattern recovered immediately after the termination of current injection. The dotted horizontal line on each trace indicates $0 \mathrm{mV}$. $\boldsymbol{B}$, When the neurons were quiescent, depolarization of both Si1s (1 $\mathrm{nA})$ caused them to spike and induced a swim motor pattern as recorded in both Sizs and Si3s. When the current injection ended, the swim motor gradually halted. C, At the onset of Si1 stimulation, spikes in L-Si1 evoked unitary EPSPS in $\mathrm{Si} 3$ as indicated by dotted lines. These EPSPs summated in Si3 to produce action potentials, which evoked one-for-one EPSPs in Si2, causing it to fire action potentials. Data in $\boldsymbol{A}$ and $\boldsymbol{B}$ were obtained from the same preparation.

synapses with both Si3s. In quiescent preparations, when Si1 spiking was induced by injecting depolarizing current, we observed EPSPs in $\mathrm{Si} 3$ that corresponded one-for-one with Sil spikes in all preparations examined (Fig. $3 C ; N=43$ ).

To determine whether the synapse from Si1 to Si3 was monosynaptic, we applied $\mathrm{Hi}-\mathrm{Di}$ saline, which raises the threshold for action potential firing and thus minimizes spontaneous activity and polysynaptic pathways (Fig. 4). Sil evoked fast and slow EPSPs in Si3 (Fig. 4A1). The fast EPSPs in both left and right Si3s followed the Sil spikes one-for-one at fixed latencies, indicating that they are monosynaptic (Fig. $4 A 2)$. The average amplitude of the Si1-evoked EPSP in the Si3 ipsilateral to Sil was $2.61 \pm 1.57 \mathrm{mV}(N=22)$ and $2.73 \pm 1.94$ $\mathrm{mV}(N=23)$ in the contralateral Si3. There was no significant difference in the Sil-evoked EPSPs between left and right Si3s ( $p=0.87$ by Mann-Whitney rank sum test). The fast EPSPs rode on top of a slow depolarizing potential that lasted for
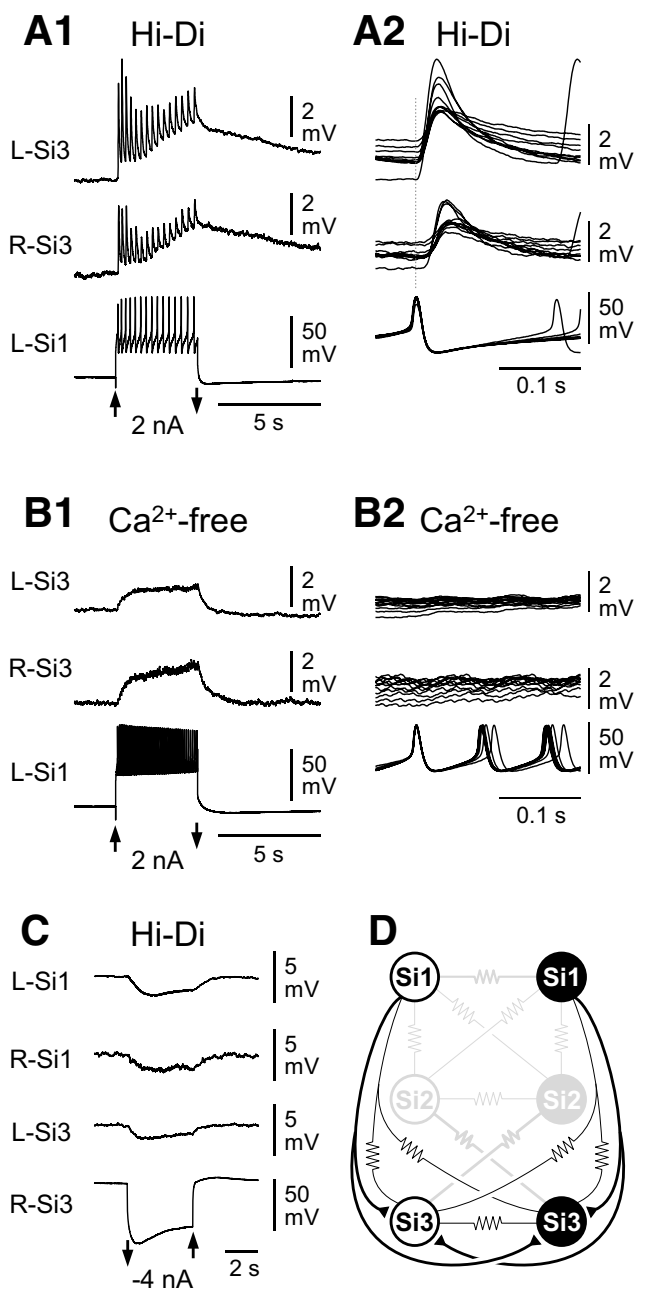

Figure 4. In Dendronotus, Si1 makes both chemical and electrical synapses onto both of the Si3s. A1, In the presence of Hi-Di saline, a spike train in the L-Si1 evoked by a $2 \mathrm{nA}$ current pulse produced a train of EPSPs in both left and right Si3s, which rode on top of a slow depolarizing potential. The slow depolarizing potential lasted for $\sim 20 \mathrm{~s}$ after termination of the depolarizing pulse. $\boldsymbol{A 2}$, Superimposed traces from $\boldsymbol{A} \mathbf{1}$, aligned to the peak of Si1 spikes, as indicated by the vertical dotted line, show the one-to-one relationship between the Si1 action potentials and synaptic responses in both Si3s. $B, \mathrm{Ca}^{2+}$-free saline blocked the chemical component of the Si1-to-Si3 synapse. B1, The fast EPSPs and the slow potential were blocked by the calcium-free saline, leaving only the electrical component. $\boldsymbol{B} 2$, Superimposed traces from B1 show the EPSPs in Si3 are largely blocked in $\mathrm{Ca}^{2+}$-free saline. C, A hyperpolarizing current pulse injected into R-Si3 produced hyperpolarization in both Si1s and the contralateral $\mathrm{Si}$. Arrows indicate onset and offset of the current pulse ( $-4 \mathrm{nA}, 4 \mathrm{~s}$ ) injected through a second electrode in R-Si3. D, A summary diagram showing newly found excitatory and electrical connections among Si1s and Si3s. Electrical connections among Si1s and Si2s and Si2s and Si3s shown in gray were previously established (Sakurai et al., 2011; Sakurai and Katz, 2016).

$>10 \mathrm{~s}$ (Fig. 4A1). The amplitude of the slow component evoked by a Si3 spike train $(5 \mathrm{~Hz}, 5 \mathrm{~s})$ was $5.61 \pm 2.72 \mathrm{mV}(\mathrm{N}=$ $8)$. The decay time to $50 \%$ was $5.47 \pm 2.44 \mathrm{~s}(N=8)$. Both the fast and slow components of Sil-evoked EPSPs in Si3 were greatly diminished in $\mathrm{Ca}^{2+}$-free saline, suggesting that they are mediated by chemical synapses (Fig. $4 B ; N=11$ ).

The $\mathrm{Ca}^{2+}$-free saline also revealed an electrotonic component of the excitatory connection between Sil and both Si3s (Fig. 4B1; $N=11$ ). The electrical synapse was symmetrical; hyperpolarizing current injected into one Si3 produced electrotonic potentials in the contralateral Si3 and both Sils (Fig. 4C). There was no significant difference in the strength of electrical coupling between the 

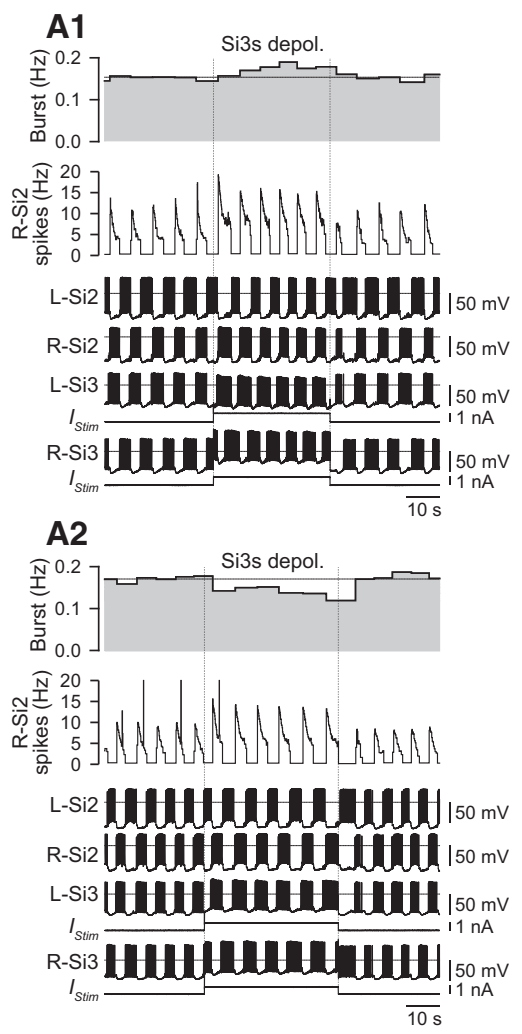

B
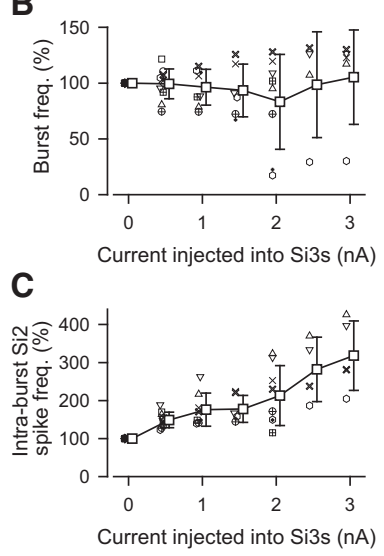

Figure 5. In Dendronotus, depolarization of both Si3s did not produce a consistent effect on the burst frequency. $A$, Depolarization of both Si3s by current injection $(1 \mathrm{nA})$ increased the cycle frequency of an ongoing swim motor pattern in one preparation $(\boldsymbol{A} \mathbf{1})$, but decreased it in another preparation (A2). In both preparations, the membrane potential activity of four neurons ( $\mathrm{Si} 2$ and $\mathrm{Si} 3$ ) were recorded simultaneously. Plots above the traces show the instantaneous frequencies of burst cycle (top plot) and spikes (bottom plot) in R-Si2. The vertical dotted lines indicate the duration of Si3 depolarization. The horizontal dotted lines indicate $0 \mathrm{mV}$ for the recordings and average baseline burst frequencies for the instantaneous burst frequency. $\boldsymbol{B}$, Depolarizing current injection showed no significant change in the burst frequency $(p=0.86$ by one-way repeated-measures ANOVA, $F_{(6,36)}=0.42, N=11$ ). The burst frequency was measured from R-Si2 in all preparations. $C$, The Si2 intraburst spike frequency increased as a function of depolarizing current injection into $\mathrm{Si} 3(p<0.001$ by one-way repeated-measures ANOVA, $\left.F_{(6,36)}=19.5, N=11\right)$.

ipsilateral and contralateral neurons; the coupling coefficient between Sil and the contralateral Si3 was $0.023 \pm 0.011(N=9)$ and $0.021 \pm 0.008(N=7)$ between Sil and the ipsilateral Si3 (onetailed, $p=0.32$ by Student's $t$ test). In $\mathrm{Ca}^{2+}$-free saline, Sil spikes produced small depolarizing potentials (Fig. 4B2), which were mediated by electrical connections. The average amplitude of such depolarizing potentials in the Si3 ipsilateral to Sil was

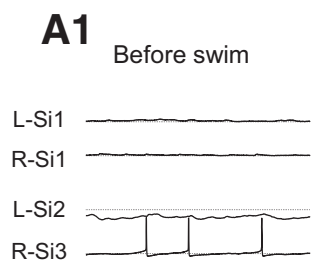

B1
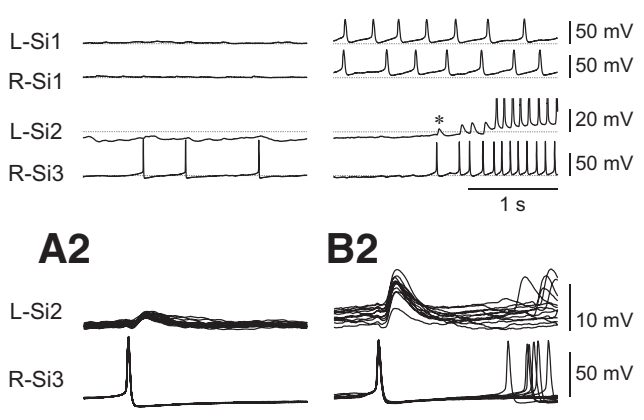

\section{B2}

C
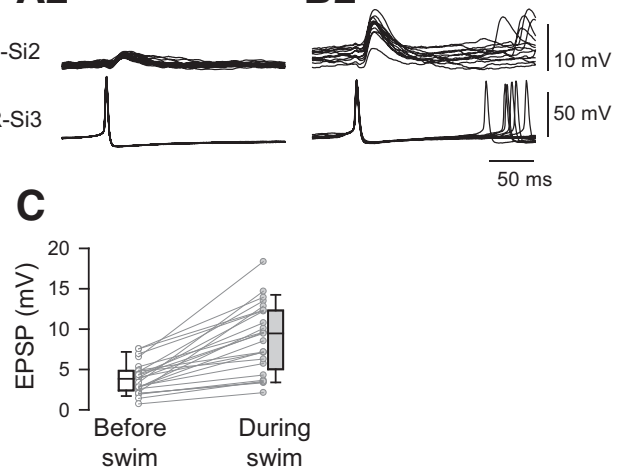

Figure 6. In Dendronotus, the Si3-to-Si2 synaptic potentials increased in amplitude during the swim motor pattern. $\boldsymbol{A 1}$, Before the swim motor pattern, the Si3-evoked small EPSPs in Si2 are difficult to see. $\mathbf{A 2}$, Twenty overlaid traces revealed the Siz-evoked EPSPs in Si2. The EPSPS were $<5 \mathrm{mV}$ and were time-locked to the Si3 spikes in Si2. B1, During the swim motor pattern, both Si1s fired action potentials and the Si3-evoked EPSPs were clearly visible in Si2 at the onset of each burst. B2, Overlaid traces of the first EPSP each Si2 burst over 13 cycles show that they increased in amplitude up to $\sim 10 \mathrm{mV}$. In $\boldsymbol{A} \mathbf{1}$ and $\boldsymbol{B} \mathbf{1}$, the horizontal dotted lines indicate -50 $\mathrm{mV}$. C, The average amplitudes of the Si3-evoked EPSPs in Si2 before and during the swim motor pattern. In each preparation, the average EPSP amplitude was obtained from 10 spontaneous EPSPs before the swim motor pattern and from the initial EPSP in 10 bursts after the onset of the swim motor pattern ( $B$ 1, asterisk). Wilcoxon signed rank test shows a statistically significant difference $(p<0.001, W=325.0, Z$ statistic $=4.372, N=25)$.

$0.27 \pm 0.20 \mathrm{mV}(N=9)$ and $0.34 \pm 0.18 \mathrm{mV}(N=8)$ in the contralateral Si3. There was no significant difference between left and right Si3s in the size of Sil-evoked electrotonic potentials (one-tailed, $p=0.23$ by Student's $t$ test). Thus, the excitatory action from Sil to Si3 that is mediated by electrical coupling is approximately one-tenth the size of the chemical excitatory synaptic action. These results suggest that each Sil equally drives both the left and right Si3 via excitatory synapses and electrical coupling, but the excitatory action is mediated mainly through chemical synapses (Fig. 4D).

\section{Depolarization of Si3 does not account for the Sil-evoked acceleration of the motor pattern}

Sil stimulation accelerates an ongoing swim motor pattern (Fig. 1B2; Sakurai et al., 2011). To determine whether this effect on the swim motor program is caused by the synaptic actions of Sil on Si3, we mimicked the Sil-induced synaptic depolarization by depolarizing both Si3s with positive current injection. Bilateral depolarization of $\mathrm{Si3}$ did not consistently mimic the effect of $\mathrm{Si} 1$ stimulation, increasing burst frequency in $46 \%$ of preparations (Fig. $5 A 1 ; N=5$ of 11 ) and decreasing it in $36 \%$ of preparations (Fig. $5 A 2 ; N=4$ ). In two preparations, the effect changed from trial to trial. Overall, there was no clear effect of bilateral Si3 depolarization on the swim cycle frequency (Fig. 5B). However, current injection caused a significant increase in the intraburst spike frequency of Si3 (Fig. 5C; $p<0.001$ by one-way repeatedmeasures ANOVA, $F_{(6,36)}=19.5, N=11$ preparations). These results suggest that $\mathrm{Si} 1$-evoked depolarization of $\mathrm{Si} 3$ increases the 
firing rate within every burst but does not change the frequency of the bursts.

\section{Sil potentiates the $\mathrm{Si3}-$ to-Si2 synapse}

Previously it was shown that the synapse from $\mathrm{Si} 3$ to the contralateral $\mathrm{Si} 2$ is necessary for the CPG to produce the swim motor pattern (Sakurai and Katz, 2016). Here, we found that in all preparations examined, this synaptic potential increased in amplitude during the swim motor pattern (Fig. $6 A-C$; $N=25$ preparations). Before the occurrence of the swim motor pattern, sparse spiking of $\mathrm{Si} 3$ evoked small EPSPs in Si2 (Fig. 6A1), which can be seen when overlaid (Fig. 6A2). During the swim motor pattern, the Si3-evoked EPSPs in Si2 increased in amplitude (Fig. 6B1), corresponding one-toone with the Si3 spikes (Fig. 6B2). Overall, the amplitude of the initial EPSP during the swim motor pattern was $8.9 \pm 4.3 \mathrm{mV}$ $(N=25)$, which was significantly larger than those evoked before a swim motor pattern $3.9 \pm 1.9 \mathrm{mV}$ (Fig. $6 C ; N=25$, $\mathrm{W}=325, p<0.001$ by Wilcoxon signed rank test, $N=25$ ). This increase might have been due at least in part to activitydependent facilitation of the Si3 synapse. However, because Sil activity was tightly correlated with the swim motor pattern (compare Fig. 2), it was also feasible that Sil had a neuromodulatory action on the synapse. Therefore, we examined the direct effect of Sil onto the $\mathrm{Si} 3$ synaptic strength while suppressing spontaneous activity with Hi-Di saline (Fig. 7).

To measure Si3 synaptic strength, Si2 was voltage-clamped at $-50 \mathrm{mV}$ in $\mathrm{Hi}$-Di saline while $\mathrm{Si} 3$ was stimulated to fire one action potential every $5 \mathrm{~s}$ (Fig. 7A). The Si3-evoked EPSCs maintained a constant amplitude until Sil was stimulated to fire a train of action potentials $(5 \mathrm{~Hz}, 5 \mathrm{~s})$, causing a large increase in the amplitude of the EPSCs (Fig. 7A-C). The magnitude of the increase varied across preparations; the average EPSC amplitude $5 \mathrm{~s}$ before Si1 stimulation was $0.73 \pm 0.45 \mathrm{nA}$, which increased to $1.22 \pm 0.56 \mathrm{nA} 5 \mathrm{~s}$ after the stimulation ( $p=0.004$ by a two-tailed paired $t$ test, $N=4$ ). Similar results were obtained by measuring Si3-evoked EPSPs in Si2 (Fig. 7D). The average EPSP amplitude $5 \mathrm{~s}$ before Sil stimulation was $3.90 \pm 1.25 \mathrm{mV}$, which increased to $6.06 \pm 2.15 \mathrm{mV}$ ( $p=0.001$ by a two-tailed paired $t$ test, $N=9$ ). In both cases, the potentiation lasted $\sim 1 \mathrm{~min}$ (Fig. $7 C, D$ ). The Sil stimulation also caused a small increase in the input resistance of Si2 (4.4 \pm $1.7 \%, N=5$ preparations). Although the increased input resistance of the postsynaptic Si2 may have contributed to the enhancement of EPSPs, the transient large increase in synaptic current suggests that Sil directly enhances transmitter release from $\mathrm{Si} 3$ or modifies the response of receptors in $\mathrm{Si} 2$.
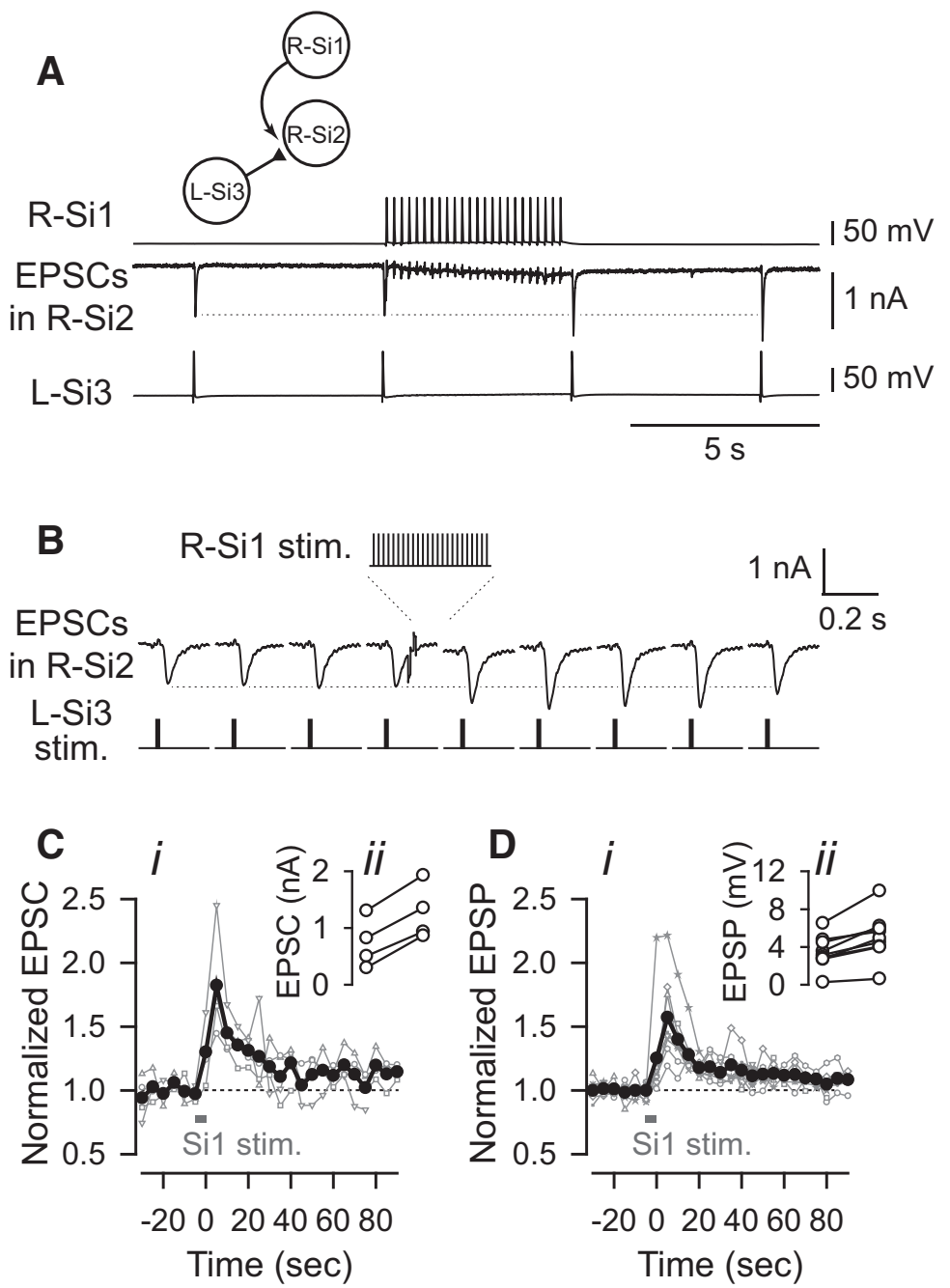

Figure 7. In Dendronotus, Si1 heterosynaptically potentiates the Si3-to-Si2 synapse. $\boldsymbol{A}$, The inset diagram above the traces shows the relevant synaptic connections among R-Si1, R-Si2, and L-Si3. The traces show simultaneous membrane potential recordings from R-Si1 (top) and L-Si3 (bottom), and the membrane current in R-Si2 (middle) that was voltageclamped at $-50 \mathrm{mV}$. Si3 was stimulated with brief current pulses to fire one action potential every $5 \mathrm{~s}$. Each $\mathrm{Si} 3$ spike produced an EPSC of a relatively constant amplitude in Si2. An Si1 spike train ( $5 \mathrm{~Hz} ; 4.6 \mathrm{~s}$ ) was imposed between the sixth and seventh Si3 stimuli (the 1st through 4th stimuli are not shown). Shortly after the stimulation of Si1, the amplitude of EPSC increased. $\boldsymbol{B}$, Expanded time base for the Si3-evoked EPSCS. After the Si1 spike train, the amplitudes of the EPSCS increased. The potentiation lasted for $\sim 20 \mathrm{~s}$ after the Si1 spike train and then declined. $\boldsymbol{C}$, Normalized amplitudes of Si3-evoked EPSCS $(N=4)$ transiently increased after the Si1 spike train (gray rectangle). The black plot represents the mean of data obtained from four preparations; gray plots show individual data. Amplitudes were normalized to the average of the six EPSCs elicited before each Si1 spike train. Cii, Changes in the amplitudes of the Si3-evoked EPSCs immediately before (left) and $5 \mathrm{~s}$ after (right) the Si1 stimulation. In all cases, the EPSC increased in amplitude (two-tailed, $p<0.001$ by paired $t$ test, $N=4)$. Di, The Si1-evoked transient increase of the normalized amplitude of Si3-evoked EPSPs $(N=9)$. The black plot represents the mean of data obtained from nine preparations; gray plots show individual data. Dii, Changes in the EPSP amplitude immediately before (left) and $5 \mathrm{~s}$ after (right) the Si1 stimulation. In all cases, the EPSP increased in amplitude (two-tailed, $p<0.001$ by paired $t$ test, $N=9$ ).

\section{Sil accelerates the swim motor pattern by potentiating the} Si3-to-Si2 synapses

To determine the effects of increasing the strength of the Si3-toSi2 synapses on the swim motor pattern, we performed a "virtual neuromodulation" experiment by artificially increasing the synaptic conductance using the dynamic clamp (Fig. 8). For the dynamic clamp, the amplitude and time course of the synaptic current was calculated in real time (see Materials and Methods) and injected into the postsynaptic Si2 through a second electrode in response to spikes in $\mathrm{Si} 3$. 
A

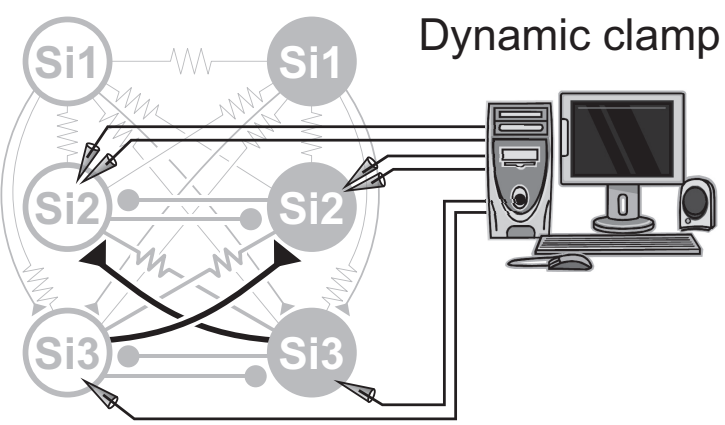

B
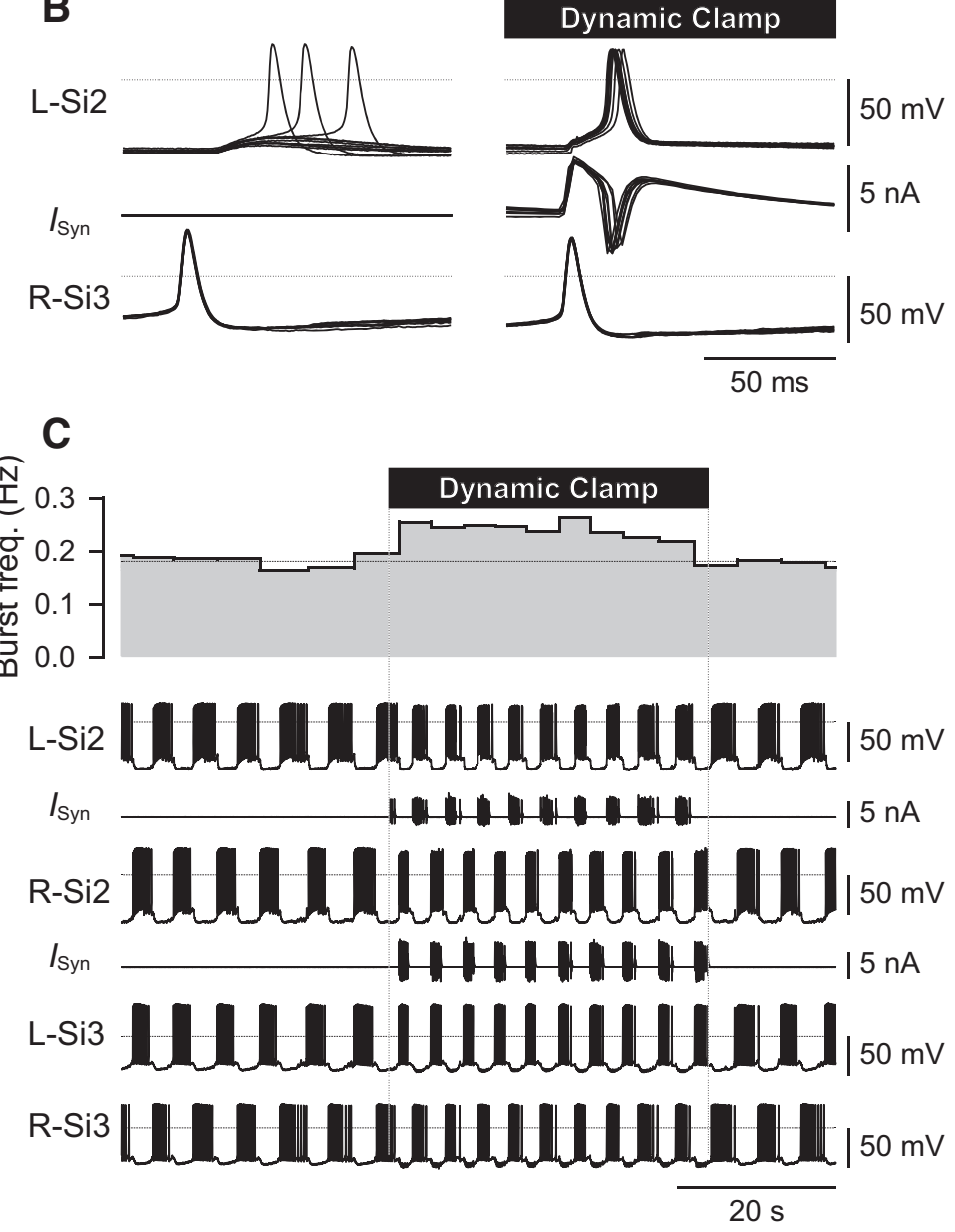

D1

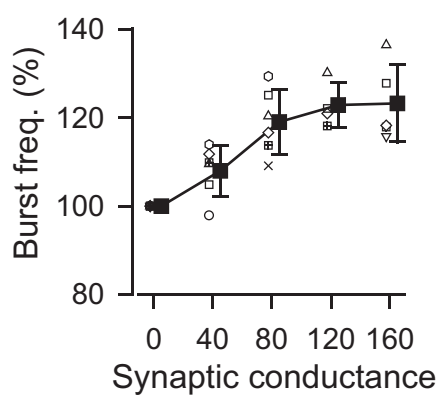

(nS)
D2

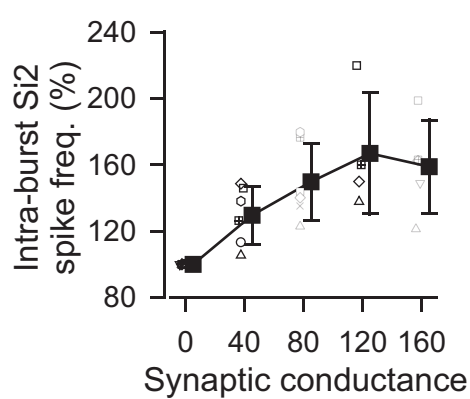

$(\mathrm{nS})$

Figure 8. In Dendronotus, virtual neuromodulation of the Si3-to-Si2 synapses by dynamic clamp accelerates the swim motor pattern. $\boldsymbol{A}$, The experimental arrangement for dynamic clamp is shown. (see Materials and Methods for details.) Every time the membrane potential $\left(V_{m}\right)$ of Si3 surpassed a specified threshold ( $50 \%$ of spike height), an artificial synaptic current $\left(I_{\text {Syn }}\right)$ was

When the Si3-to-Si2 synapse was artificially boosted, $\mathrm{Si} 2$ became more likely to fire an action potential in response to $\mathrm{Si} 3$ spiking (Fig. 8B; Sakurai and Katz, 2016). Artificial enhancement of both Si3-to-Si2 synapses accelerated the swim motor pattern (Fig. 8C). The burst frequency (Fig. $8 D 1)$ and the intraburst spike frequency (Fig. 8D2) of Si2 increased as the artificial synaptic conductance was increased $(N=$ 8 preparations). This demonstrates that increasing the strength of the Si3-to-Si2 synapse alone is sufficient to increase the burst frequency and the intraburst spike frequency.

\section{Combined depolarization of $\mathrm{Si} 3$ and} potentiation of $\mathrm{Si} 3$ synapse is sufficient to evoke the swim motor pattern

In a previous study, we demonstrated that depolarization of both Si2s caused them to fire bursts of long duration that irregularly alternated between the left and right sides. Activation of spiking in the Si3 pair alone did not induce bursting unless the Si2s were also recruited by the excitatory Si3-to-Si2 synapse (Sakurai and Katz, 2016). Here, in a similar experiment, we show that spiking activity in the Si3s alone did not initiate or maintain the swim motor pattern (Fig. 9A1) unless it was strong enough to recruit spiking in the Si2s (Fig. 9A2). Thus, although the Si3 pair is reciprocally inhibitory, it is not sufficient to produce rhythmic bursting; the CPG requires the participation of Si2s firing with Si3s to produce rhythmic bursting activ-

calculated by the computer and injected into the contralateral Si2 to boost the existing Si3-to-Si2 synapse (black connections). $\boldsymbol{B}$, Overlaid traces of membrane potential recordings from L-Si2 and R-Si3 and the artificial synaptic current $\left(I_{\text {syn }}\right)$ before (left) and during (right) dynamic clamp. When an artificial synaptic conductance (160 nS) was introduced with the dynamic clamp, Si3 spikes reliably triggered one-for-one Si2 spikes. C, A plot of instantaneous cycle frequency (top) obtained from simultaneous intracellular recording from all four neurons (bottom) shows the effect of dynamic clamping (black bar). The synaptic boost caused by adding artificial synaptic conductance ( $160 \mathrm{nS}$ ) with the dynamic clamping accelerated the swim motor pattern. The horizontal dotted line in the plot indicates the average cycle frequency before dynamic clamping, and $0 \mathrm{mV}$ in the recordings. The vertical dotted lines indicate the duration of dynamic clamping. $\boldsymbol{D}$, Boosting the synaptic conductance from Si3 to Si2 increased both the burst frequency (D1) and the Si2 intraburst spike frequency (D2). The burst frequency increased to a maximum of $123 \%$ of baseline by adding an artificial synaptic conductance of $160 \mathrm{nS}$ (D1; $p<0.001$ by one-way repeated-measures ANOVA, $F_{(4,17)}=$ $20.9, N=8)$. The intraburst spike frequency increased to a maximum of $\sim 167 \%$ of baseline (D2; $p<0.001$ by one-way repeated-measures ANOVA, $\left.F_{(4,17)}=12.1, N=8\right)$. Open symbols represent individual preparations. 
ity. Because Sil has neuromodulatory actions that potentiate Si3-to-Si2 synapses in addition to depolarizing Si3, we examined the effect of synaptic potentiation of generation of the swim motor pattern.

When the Si3s were both depolarized by bilateral current injection, boosting the Si3-to-Si2 synapses by dynamic clamping induced the swim motor pattern by allowing the Si3s to more easily recruit the Si2s (Fig. 9B1). With dynamic clamping, as little as $0.5 \mathrm{nA}$ injected into both Si3s evoked bursting in $100 \%$ of preparations (Fig. $9 C$, black squares). Injection of $2 \mathrm{nA}$ current alone induced rhythmic bursting in $>50 \%$ of preparations (Fig. 9A2,C, white circles). Once initiated, burst frequency did not increase as a function of current injected into Si3 either with or without dynamic clamping (Fig. 9B2,D). Without dynamic clamping, the Si2 intraburst spike frequency showed no significant change with larger injected currents $(N=$ 11 preparations); however, with dynamic clamping it increased with larger injected current ( $N=7$ preparations; Fig. $9 E)$. Thus, Sil acts via a combination of actions to initiate and maintain the swim motor pattern: depolarization of $\mathrm{Si3}$ and enhancement of Si3 synaptic strength. The depolarization of $\mathrm{Si} 3$ is crucial for the initiation of spiking activity whereas the synaptic potentiation allows $\mathrm{Si} 3$ to reliably recruit robust $\mathrm{Si} 2$ spiking.

\section{Discussion}

Despite being homologous in Dendronotus and Melibe, Sil has different functions in the generation of homologous swimming behaviors in these two nudibranch species (Sakurai et al., 2011). In Dendronotus, Sil is not part of the swim CPG; it does not fire bursts of action potentials in phase with the motor pattern and it lacks reciprocal inhibition across the midline (Sakurai et al., 2011). Here, we showed that Sil acts as an extrinsic command-like neuron whose non-rhythmic activity is necessary and sufficient for the swim CPG to produce a rhythmic motor pattern.

In Melibe, it was previously shown that Sil acts as a member of the swim CPG, exhibiting bursting activity during the swim motor pattern, which is maintained through reciprocal inhibition with the contralateral Si1 and Si2 and strong electrical coupling with the ipsilateral Si2 (Thompson and Watson, 2005; Sakurai et al., 2011, 2014). Each Si1 synapses bilaterally onto the Si3 pair, but their actions are opposite between left and right Si3; Si1 makes an excitatory synapse onto the ipsilateral $\mathrm{Si} 3$ and a biphasic synapse onto the contralateral Si3 (Fig. 1A1; Sakurai et al., 2014). These asymmetric synapses in Melibe play a role in

B1
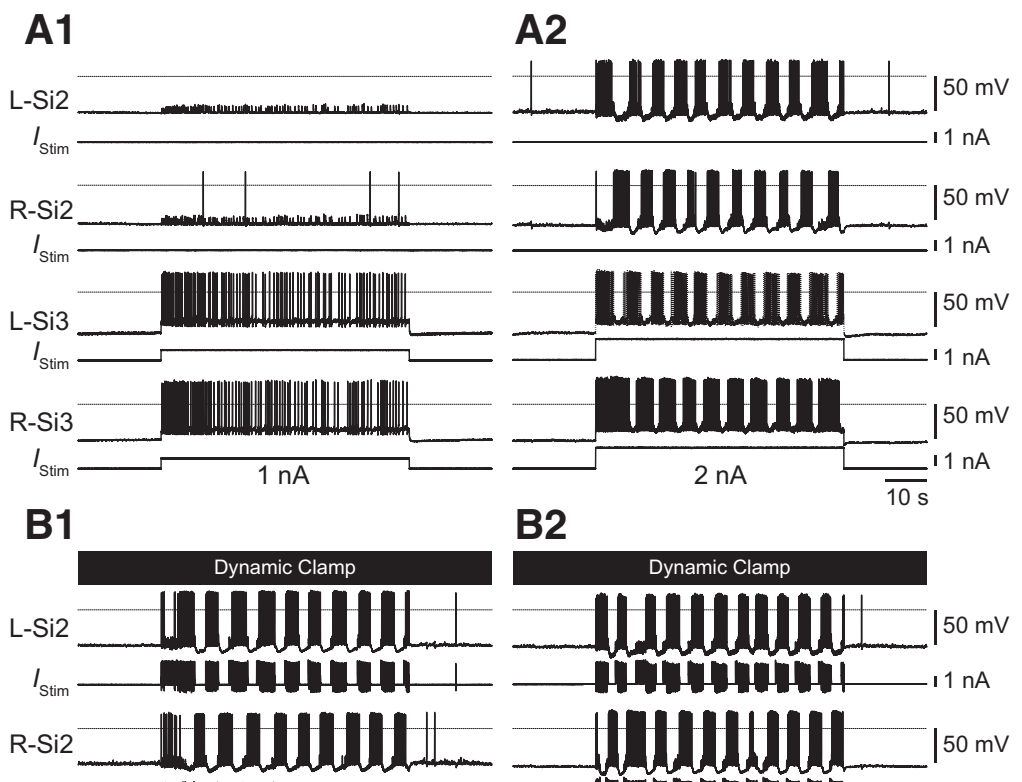

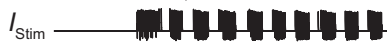
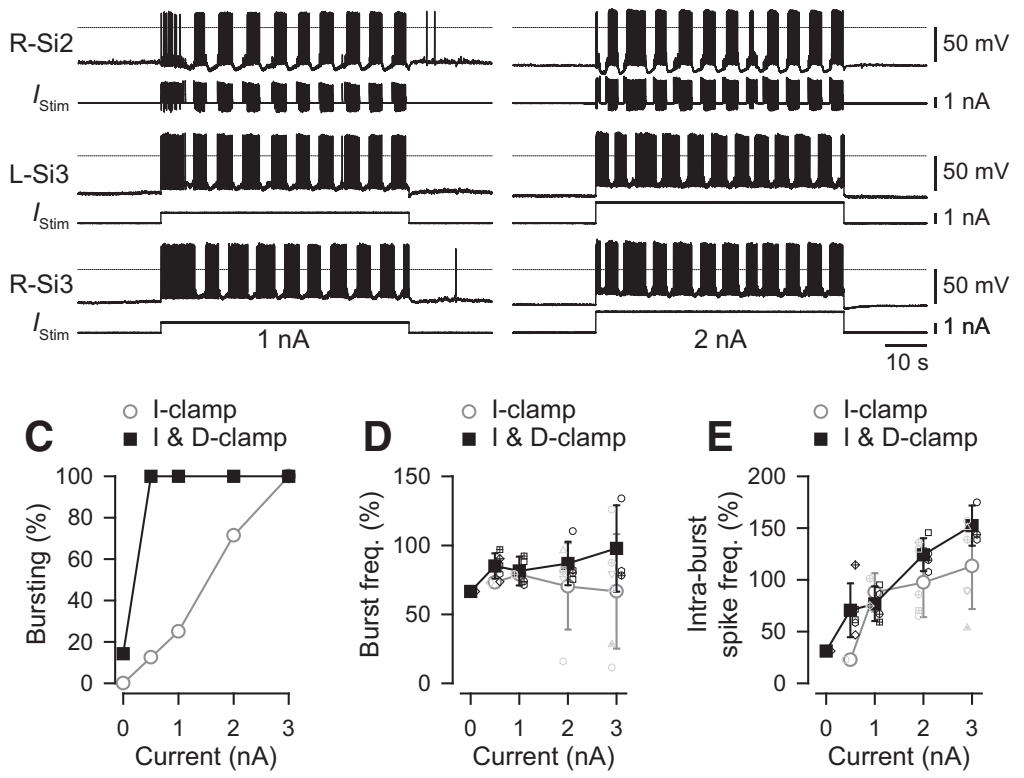

Figure 9. In Dendronotus, bilateral Si3 depolarization and synaptic boosting evokes the swim motor pattern. $\boldsymbol{A}$, Simultaneous intracellular microelectrode recordings from both $\mathrm{Si} 2 \mathrm{~s}$ and $\mathrm{Si} 3$ shows that bilateral depolarization of the Si3s alone with $1 \mathrm{nA}$ did not trigger rhythmic bursting (A1), but in this preparation $2 \mathrm{nA}$ did cause bursting (A2). $\boldsymbol{B}$, Boosting the Si3-to-Si2 synapses alone by dynamic clamping (black bar; $I_{\text {syn }}=40 \mathrm{nS}$ ) did not evoke bursting, but as soon as the Si3s were depolarized with current injection (1 nA), rhythmic bursting was initiated (B1). When the depolarizing current was turned off, the rhythmic bursting stopped. Increasing the current step in $\mathrm{Si} 3$ to $2 \mathrm{nA}$ did not have an additional effect on the bursting (B2). The traces in $\boldsymbol{A}$ and $\boldsymbol{B}$ were obtained from the same preparation. $C$, The percentage of preparations that showed rhythmic bursting of Si2s and Si3s in response to current injection in Si3 increased as a function of current (open gray circles). With dynamic clamping $\left(I_{\text {Syn }}=40 \mathrm{nS}\right)$, all preparations showed the swim motor pattern with current injection of $0.5 \mathrm{nA}$ or higher (filled squares). For l-clamp, $N=11(0 \mathrm{nA})$, $8(0.5 \mathrm{nA}), 8(1 \mathrm{nA}), 7(2 \mathrm{nA}), 6(3 \mathrm{nA})$; for I \& D-clamp, $N=7(0 \mathrm{nA}), 5(0.5 \mathrm{nA}), 4(1 \mathrm{nA}), 4(2 \mathrm{nA}), 3(3 \mathrm{nA}) . \mathrm{D}$, In the preparations that exhibited rhythmic bursting, burst frequency did not increase as a function of current injected into both Si3s either alone (open gray circles; $p=0.66$ by one-way repeated-measures ANOVA, $F_{(2,4)}=0.46$ ) or with dynamic clamp (filled squares; $p=0.54$ by one-way repeated-measures ANOVA, $\left.F_{(4,6)}=0.85\right)$. $\boldsymbol{E}$, In the preparations that exhibited rhythmic bursting, the intraburst spike frequency of $\mathrm{Si} 2$ increased as a function of current injected into the Si3s when dynamic clamp was imposed (black squares; $p=$ 0.005 by one-way repeated-measures ANOVA, $\left.F_{(4,6)}=12.2\right)$. Without dynamic clamping, the intraburst spike frequency showed no significant change with increased amount of current (open gray circles; $\left.p=0.14, F_{(2,4)}=3.30\right)$. $C$ - $\boldsymbol{E}$ Graphs were made from the same set of data. In $\boldsymbol{D}$ and $\boldsymbol{E}$, small open symbols represent individual preparations.

promoting the transition of $\mathrm{Si} 3$ bursting from one side to the other and thus are important for setting the phase relationship between two half-center kernels (Sakurai et al., 2014). Thus, homologous neurons in these two species differ in their functional positions in the motor system hierarchy; Sil is part of the swim CPG in Melibe, but serves as a higher-level command neuron in Dendronotus. 
A

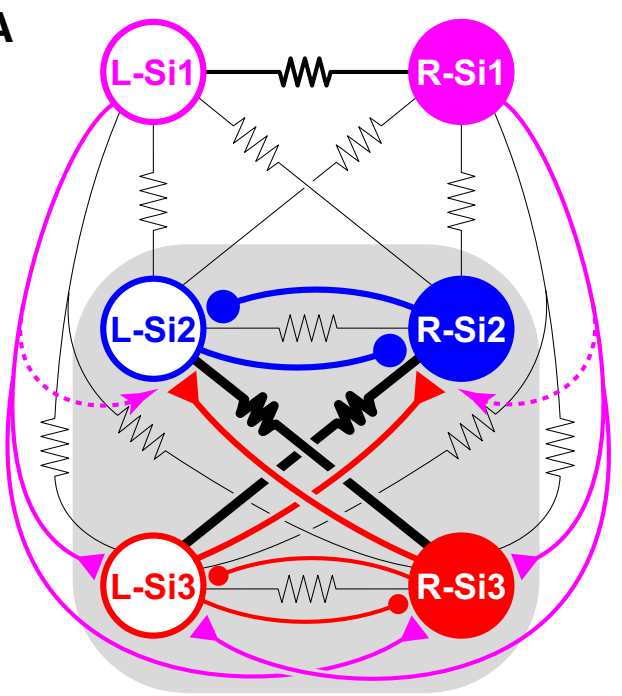

B

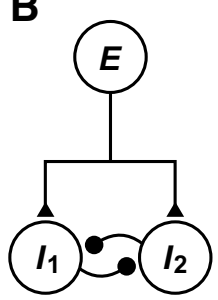

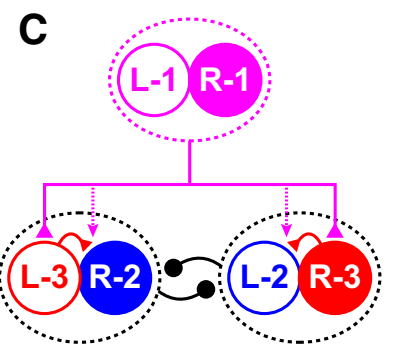

Figure 10. In Dendronotus, the Si1s serve as command neurons to a half-center oscillator. $\boldsymbol{A}$, An updated diagram of the Dendronotus swim CPG showing all of the monosynaptic connections and neuromodulation. $\boldsymbol{B}$, A classical model of the half-center oscillator, in which interneurons $\left(\mathrm{I}_{1}\right.$ and $\left.\mathrm{I}_{2}\right)$ are coupled by reciprocal inhibitory synapses and can generate alternating oscillatory activity when they equally receive tonic excitatory drive from E (Brown, 1911; Friesen, 1994). C, A condensed version of the Dendronotus swim CPG, in which the right Si2 and left $\mathrm{Si} 3(\mathrm{R}-2, \mathrm{~L}-3)$ are grouped into a functional unit as are their contralateral counterparts (black dashed ovals). Within each functional unit, the contralateral Si2 and Si3 form mutually excitatory connections via electrical and chemical synapses. The paired functional units form reciprocal inhibition; Si2 and Si3 each inhibit its contralateral counterpart. The Si1 pair provides comparable excitatory drive and neuromodulation to both the left and right sides.

\section{Dual actions by Sil activate the motor pattern}

In Dendronotus, each Sil has two complementary bilateral actions (Fig. 10A). The first action of Sil is to evoke fast and slow excitatory potentials in both Si3s, which summate to cause them to fire action potentials. The second action of Sil is to heterosynaptically potentiate the Si3-to-Si2 synapses. This potentiation is necessary to allow Si3 to excite Si2 above threshold for firing action potentials. Mimicking these two actions by depolarization of Si3s and dynamic clamping of the Si3-to-Si2 synapses elicits a swim-like motor pattern. Thus, the dual effects of Sil, depolarizing Si3 and enhancing its synaptic strength, are sufficient for the CPG to produce rhythmic bursting activity.

Because Sil has electrical coupling with all other neurons involved in the circuit, it is likely that the electrical coupling also contributes to generation of the swim motor pattern to some extent. However, based on the facts that (1) the chemical synaptic potentials are $\sim 10$ times larger than the electrotonic potentials and that (2) the swim motor pattern can be blocked by reducing the strength of the Si3-to-Si2 chemical synapse either by pharmacological manipulation (Sakurai and Katz, 2017) or by dynamic clamping (Sakurai and Katz, 2016), we conclude that Sil initiates and maintains the swim motor pattern mainly through its chem- ical synaptic action onto $\mathrm{Si} 3$ and the heterosynaptic potentiation of $\mathrm{Si} 3$ synapses.

Activation of Sil also accelerates the on-going swim motor pattern. In this study, we demonstrated that artificially boosting the Si3-to-Si2 synapses by dynamic clamping mimicked the acceleratory effect of Si1, but simple bilateral depolarization of Si3s did not. In the Dendronotus swim CPG, it was previously shown that neither $\mathrm{Si} 2$ nor $\mathrm{Si} 3$ possesses any endogenous bursting properties, but action potential firing in both neurons is essential to generate rhythmic bursting (Sakurai and Katz, 2016). It is still unclear how strengthening the excitatory synapse from $\mathrm{Si} 3$ to $\mathrm{Si} 2$ accelerates the oscillatory activity. We hypothesize that $\mathrm{Si} 3$ not only causes Si2 to fire, but also that it may boost dynamic membrane properties of $\mathrm{Si} 2$ and/or Si3. In a half-center configuration, the dynamic properties of neuronal components play crucial roles in prompting phase transitions from one side to the other (Friesen and Stent, 1978; Arbas and Calabrese, 1987; Friesen, 1994).

\section{Sil as a command neuron}

Since the early description of "command neurons" by Wiersma and Ikeda (1964), there have been many reports describing the functions of command neurons (Kupfermann and Weiss, 1978; Puhl et al., 2012; Bouvier et al., 2015; Hampel et al., 2015; Kim et al., 2017). Extrinsic command neurons are a common feature of motor systems such as leech swimming (Kristan et al., 2005), insect leg movements (Berg et al., 2015), and vertebrate locomotion (Dubuc et al., 2008; McLean et al., 2008; Hägglund et al., 2010; Kimura et al., 2013; Bouvier et al., 2015; Grillner and El Manira, 2015).

Sil fulfills the criteria for a command neuron (cf. Kupfermann and Weiss, 1978): (1) Sil always fired during the swim motor pattern. (2) Sil is necessary for production of the swim motor pattern; suppression of both Sils blocked the swim motor pattern. (3) Activation of both Sils is sufficient to initiate the swim motor pattern.

\section{The synaptic and neuromodulatory mechanism underlying the Sil command}

The Dendronotus organization closely resembles that originally proposed for a half-center oscillator with excitatory drive arising from a command neuron (Fig. 10 B, C; Friesen, 1994). In the vertebrate brainstem and spinal cord, respiratory and locomotor CPGs convert the tonic brainstem input into phasic motor patterns (Dubuc et al., 2008; Hägglund et al., 2010; Kimura et al., 2013; Grillner and El Manira, 2015; but see Soffe et al., 2009; Li et al., 2010). However, little is known about how extrinsic tonic input turns on an emergent oscillatory circuit with no intrinsically bursting neurons.

Here, we determined that the excitatory synaptic inputs onto the CPG neurons and the potentiation of their synapses mediate the command-like action of Sil. Moreover, mimicking the dual bilateral actions of Si1 by dynamic clamping induced rhythmic bursting of $\mathrm{Si} 2$ and $\mathrm{Si} 3$ that resembled the swim motor pattern. These experiments directly showed that the synaptic and neuromodulatory actions of Sil are sufficient to induce the swim motor pattern.

\section{Dendronotus command mechanism differs from that of Tritonia}

In another nudibranch, Tritonia diomedea, the mechanism for commanding a swim motor pattern separates the excitatory synaptic drive from the neuromodulation. The Dorsal Ramp In- 
terneuron (DRI) is the command neuron for dorsal-ventral flexion swimming (Frost and Katz, 1996). It evokes large EPSPs in a set of swim CPG neurons (Dorsal Swim Interneurons, DSIs) similar to the large EPSPs evoked by Sil in Si3. However, unlike Sil, DRI does not enhance the strength of synapses made by the DSIs. Instead, the DSIs themselves enhance the strength of synapses made by other CPG neurons by releasing serotonin (Katz et al., 1994; Katz and Frost, 1995a,b; Sakurai and Katz, 2003). Thus, the functionality of excitation and neuromodulation is divided between two neurons in Tritonia, one of which is intrinsic to the swim CPG, whereas in Dendronotus, a single neuron, Sil, combines both actions.

\section{The Dendronotus command is separate from the swim CPG}

The line between command neuron and CPG neuron can be blurred in some cases. Extrinsic modulatory neurons can receive rhythmic drive from the CPG causing them to oscillate when the CPG is activated (Coleman and Nusbaum, 1994; Coleman et al., 1995). In Tritonia, DRI also receives feedback from the swim CPG and has its spiking shaped by the motor pattern (Frost and Katz, 1996). In this study we found no evidence that Sil receives feedback from the CPG neurons except for electrical coupling, which is $\sim 10 \times$ weaker than the ipsilateral Sil-to-Si2 coupling in Melibe (Sakurai et al., 2011). Thus, in Dendronotus, there is a distinct separation of command and CPG function.

\section{Anatomical organization of the hierarchical structure}

It may be significant that the soma of Sil resides in the cerebral ganglion. In gastropod molluscs, command neurons tend to be in the cerebral ganglia which receive inputs from visual, tactile, chemical, and vestibular senses. For example, several identified neurons in the cerebral ganglia of the pteropod Clione project axons to the pedal ganglia to control the swim motor pattern (Panchin et al., 1995; Satterlie and Norekian, 1995; Deliagina et al., 1998). Similarly, a group of neurons in the cerebral ganglion of Aplysia were shown to be necessary and sufficient to elicit for locomotor activity from the pedal ganglia (Fredman and JahanParwar, 1983; Jing et al., 2008). Command neurons for the feeding motor network in the buccal ganglia are also found in the cerebral ganglia in Aplysia (Jing et al., 2004), Pleurobranchaea (Gillette et al., 1978, 1982), Lymnaea (Norekian and Satterlie, 1993), and Clione (Alania et al., 2008). The somata of the CPG neurons $\mathrm{Si} 2$ and $\mathrm{Si} 3$ are located in the pedal ganglia, which is where efferent neurons in gastropods generally reside.

The presence of $\mathrm{Sil}$ in the cerebral ganglion suggests that Dendronotus might represent the ancestral state with Sil having a command role. Sil in Melibe might have been co-opted into a rhythmic CPG role (Sakurai et al., 2014). It would also be interesting to know how the motor hierarchy is organized in other species, such as Flabellina iodinea, which evolved the swimming behavior independently of Dendronotus and Melibe and has a rhythmically active Sil (Gunaratne et al., 2017). More species need to be sampled to better ascertain the direction of evolutionary change.

\section{References}

Alania M, Vorontsov DD, Sakharov DA (2008) Higher-order control of the feeding network in Lymnaea. Acta Biol Hung 59:23-28.

Arbas EA, Calabrese RL (1987) Ionic conductances underlying the activity of interneurons that control heartbeat in the medicinal leech. J Neurosci $7: 3945-3952$.

Berg EM, Hooper SL, Schmidt J, Büschges A (2015) A leg-local neural mechanism mediates the decision to search in stick insects. Curr Biol 25:2012-2017.
Bouvier J, Caggiano V, Leiras R, Caldeira V, Bellardita C, Balueva K, Fuchs A, Kiehn O (2015) Descending command neurons in the brainstem that halt locomotion. Cell 163:1191-1203.

Brown TG (1911) The intrinsic factors in the act of progression in the mammal. Proc R Soc Lond B 84:308-319.

Bulloch AGM, Ridgway RL (1995) Comparative aspects of gastropod neurobiology. In: The nervous systems of invertebrates: an evolutionary and comparative approach: with a coda written by T.H. Bullock (Breidbach O, Kutsch W, eds), pp 89-113. Basel: Birkhäuser Basel.

Coleman MJ, Nusbaum MP (1994) Functional consequences of compartmentalization of synaptic input. J Neurosci 14:6544-6552.

Coleman MJ, Meyrand P, Nusbaum MP (1995) A switch between two modes of synaptic transmission mediated by presynaptic inhibition. Nature 378:502-505.

Creswell RL (1993) Aquaculture desk reference. New York: Van Nostrand Reinhold.

Croll RP (1987) Identified neurons and cellular homologies. In: Nervous systems in invertebrates (Ali MA, ed), pp 41-59. New York: Plenum.

Deliagina TG, Arshavsky YI, Orlovsky GN (1998) Control of spatial orientation in a mollusc. Nature 393:172-175.

Destexhe A, Mainen ZF, Sejnowski TJ (1994) An efficient method for computing synaptic conductances based on a kinetic model of receptor binding. Neural Comput 6:14-18.

Dubuc R, Brocard F, Antri M, Fénelon K, Gariépy JF, Smetana R, Ménard A, Le Ray D, Viana Di Prisco G, Pearlstein E, Sirota MG, Derjean D, St-Pierre M, Zielinski B, Auclair F, Veilleux D (2008) Initiation of locomotion in lampreys. Brain Res Rev 57:172-182.

Fredman SM, Jahan-Parwar B (1983) Command neurons for locomotion in Aplysia. J Neurophysiol 49:1092-1117.

Friesen WO (1994) Reciprocal inhibition: a mechanism underlying oscillatory animal movements. Neurosci Biobehav Rev 18:547-553.

Friesen WO, Stent GS (1978) Neural circuits for generating rhythmic movements. Annu Rev Biophys Bioeng 7:37-61.

Frost WN, Katz PS (1996) Single neuron control over a complex motor program. Proc Natl Acad Sci U S A 93:422-426.

Gamkrelidze GN, Laurienti PJ, Blankenship JE (1995) Identification and characterization of cerebral ganglion neurons that induce swimming and modulate swim-related pedal ganglion neurons in Aplysia brasiliana. J Neurophysiol 74:1444-1462.

Gillette R, Kovac MP, Davis WJ (1978) Command neurons in Pleurobranchaea receive synaptic feedback from the motor network they excite. Science 199:798-801.

Gillette R, Kovac MP, Davis WJ (1982) Control of feeding motor output by paracerebral neurons in brain of Pleurobranchaea californica. J Neurophysiol 47:885-908.

Goodheart JA, Bazinet AL, Collins AG, Cummings MP (2015) Relationships within cladobranchia (gastropoda: nudibranchia) based on RNAseq data: an initial investigation. R Soc Open Sci 2:150196.

Grillner S, El Manira A (2015) The intrinsic operation of the networks that make us locomote. Curr Opin Neurobiol 31:244-249.

Gunaratne CA, Sakurai A, Katz PS (2017) Variations on a theme: species differences in synaptic connectivity do not predict central pattern generator activity. J Neurophysiol 118:1123-1132.

Hägglund M, Borgius L, Dougherty KJ, Kiehn O (2010) Activation of groups of excitatory neurons in the mammalian spinal cord or hindbrain evokes locomotion. Nat Neurosci 13:246-252.

Hampel S, Franconville R, Simpson JH, Seeds AM (2015) A neural command circuit for grooming movement control. eLife 4:e08758.

Jing J, Cropper EC, Hurwitz I, Weiss KR (2004) The construction of movement with behavior-specific and behavior-independent modules. J Neurosci 24:6315-6325.

Jing J, Vilim FS, Cropper EC, Weiss KR (2008) Neural analog of arousal: persistent conditional activation of a feeding modulator by serotonergic initiators of locomotion. J Neurosci 28:12349-12361.

Katz PS, Frost WN (1995a) Intrinsic neuromodulation in the Tritonia swim CPG: the serotonergic dorsal swim interneurons act presynaptically to enhance transmitter release from interneuron C2. J Neurosci 15:60356045.

Katz PS, Frost WN (1995b) Intrinsic neuromodulation in the Tritonia swim CPG: serotonin mediates both neuromodulation and neurotransmission by the dorsal swim interneurons. J Neurophysiol 74:2281-2294. 
Katz PS, Quinlan PD (2019) The importance of identified neurons in gastropod molluscs to neuroscience. Curr Opin Neurobiol 56:1-7.

Katz PS, Getting PA, Frost WN (1994) Dynamic neuromodulation of synaptic strength intrinsic to a central pattern generator circuit. Nature 367:729-731.

Kemenes I, Marra V, Crossley M, Samu D, Staras K, Kemenes G, Nowotny T (2011) Dynamic clamp with StdpC software. Nat Protoc 6:405-417.

Kiehn O (2016) Decoding the organization of spinal circuits that control locomotion. Nat Rev Neurosci 17:224-238.

Kim LH, Sharma S, Sharples SA, Mayr KA, Kwok CHT, Whelan PJ (2017) Integration of descending command systems for the generation of context-specific locomotor behaviors. Front Neurosci 11:581.

Kimura Y, Satou C, Fujioka S, Shoji W, Umeda K, Ishizuka T, Yawo H, Higashijima S (2013) Hindbrain V2a neurons in the excitation of spinal locomotor circuits during zebrafish swimming. Curr Biol 23:843-849.

Kristan WB Jr, Calabrese RL, Friesen WO (2005) Neuronal control of leech behavior. Prog Neurobiol 76:279-327.

Kupfermann I, Weiss KR (1978) The command neuron concept. Behav Brain Sci 1:3-39.

Li WC, Roberts A, Soffe SR (2010) Specific brainstem neurons switch each other into pacemaker mode to drive movement by activating NMDA receptors. J Neurosci 30:16609-16620.

McLean DL, Masino MA, Koh IY, Lindquist WB, Fetcho JR (2008) Continuous shifts in the active set of spinal interneurons during changes in locomotor speed. Nat Neurosci 11:1419-1429.

Newcomb JM, Fickbohm DJ, Katz PS (2006) Comparative mapping of serotonin-immunoreactive neurons in the central nervous systems of nudibranch molluscs. J Comp Neurol 499:485-505.

Newcomb JM, Sakurai A, Lillvis JL, Gunaratne CA, Katz PS (2012) Homology and homoplasy of swimming behaviors and neural circuits in the nudipleura (mollusca, gastropoda, opisthobranchia). Proc Natl Acad Sci U S A 109:10669-10676.

Norekian TP, Satterlie RA (1993) Cerebral neurons underlying prey capture movements in the pteropod mollusc, Clione limacina: I. Physiology, morphology. J Comp Physiol A 172:153-169.

Panchin YV, Popova LB, Deliagina TG, Orlovsky GN, Arshavsky YI (1995) Control of locomotion in marine mollusk Clione limacina: VIII. Cerebropedal neurons. J Neurophysiol 73:1912-1923.
Puhl JG, Masino MA, Mesce KA (2012) Necessary, sufficient and permissive: a single locomotor command neuron important for intersegmental coordination. J Neurosci 32:17646-17657.

Roberts A, Li WC, Soffe SR, Wolf E (2008) Origin of excitatory drive to a spinal locomotor network. Brain Res Rev 57:22-28.

Sakurai A, Katz PS (2003) Spike timing-dependent serotonergic neuromodulation of synaptic strength intrinsic to a central pattern generator circuit. J Neurosci 23:10745-10755.

Sakurai A, Katz PS (2016) The central pattern generator underlying swimming in dendronotus iris: a simple half-center network oscillator with a twist. J Neurophysiol 116:1728-1742.

Sakurai A, Katz PS (2017) Artificial synaptic rewiring demonstrates that distinct neural circuit configurations underlie homologous behaviors. Curr Biol 27:1721-1734.e3.

Sakurai A, Newcomb JM, Lillvis JL, Katz PS (2011) Different roles for homologous interneurons in species exhibiting similar rhythmic behaviors. Curr Biol 21:1036-1043.

Sakurai A, Gunaratne CA, Katz PS (2014) Two interconnected kernels of reciprocally inhibitory interneurons underlie alternating left-right swim motor pattern generation in the mollusc Melibe leonina. J Neurophysiol 112:1317-1328

Satterlie RA, Norekian TP (1995) Serotonergic modulation of swimming speed in the pteropod mollusc Clione limacina: III. Cerebral neurons. J Exp Biol 198:917-930.

Sharp AA, Skinner FK, Marder E (1996) Mechanisms of oscillation in dynamic clamp constructed two-cell half-center circuits. J Neurophysiol 76:867-883.

Soffe SR, Roberts A, Li WC (2009) Defining the excitatory neurons that drive the locomotor rhythm in a simple vertebrate: insights into the origin of reticulospinal control. J Physiol 587:4829-4844.

Stein W (2009) Modulation of stomatogastric rhythms. J Comp Physiol A Neuroethol Sens Neural Behav Physiol 195:989-1009.

Thompson S, Watson WH 3rd (2005) Central pattern generator for swimming in melibe. J Exp Biol 208:1347-1361.

Wiersma CA, Ikeda K (1964) Interneurons commanding swimmeret movements in the crayfish, Procambarus clarki (girard). Comp Biochem Physiol 12:509-525. 